\title{
Two cases with avoidant/restrictive food intake disorder (ARFID): Effectiveness of EMDR and CBT combination on eating disorders (ED)
}

\author{
Kaçıngan/Kısıtı Yiyecek Alımı Bozuklugŭ (KKYAB) Olan Iki Vaka: EMDR ve BDT \\ Kombinasyonunun Yeme Bozukluklarında (YB) Etkililiği \\ Alişan Burak Yaşar1', Ayse Enise Abamor², Fatma Dilara Usta³, Serap Erdoğan Taycan, \\ Burhanettin Kaya 5 \\ ${ }_{1}$ M.D., Marmara University Hospital, Psychiatry Clinic, Istanbul, Istanbul Turkey https://orcid.org/0000-0002-6778-3009 \\ 2M.A., Istanbul Sehir University, Institute of Social Sciences, Clinical Psychology, Istanbul, Turkey https://orcid.org/0000-0002-1242-2863 \\ 3PhD., Uskudar University, Institute of Social Sciences, Psychology, Istanbul, Turkey https://orcid.org/0000-0001-9984-8535 \\ ${ }^{4}$ Assoc. Prof., Haydarpasa Numune Research and Training Hospital, Psychiatry Clinic, Istanbul, Turkey https://orcid.org/0000-0001-7599-5821 \\ ${ }^{5}$ Assoc. Prof., Gazi University Faculty of Medicine, Psychiatry Retired Faculty Member, Ankara, Turkey https://orcid.org/0000-0002-6480-1451
}

\section{SUMMARY}

Traumatic life events are among the etiological factors that may trigger eating disorders (ED). In the present study, we examined the effects of Eye Movement Desensitization and Reprocessing (EMDR) therapy and Cognitive Behavioral Therapy (CBT) therapies combined on two young girls, who had symptoms of ED as a consequence of their traumatic experiences.

Two Caucasian female patients arrived at the clinic with highly similar complaints about eating. They both were mutually holding the fear that food would get stuck in their throat, breathing would be impeded and their heart rate would increase; creating an inability to swallow while eating. This culminated in a fear of death through asphyxiation while eating. In the initial interviews, the clients revealed past traumatic events in which a food blockage in the throat led to a temporary inability to breathe. Therefore, we conducted EMDR therapy combined with CBT. Both were treated with seven sessions of EMDR therapy and nine sessions of $\mathrm{CBT}$, after which symptoms were reduced to minimum. In this case study, EMDR therapy combined with CBT proved to be effective by neutralizing the impact of previous trauma on ED symptomatology.

Key Words: Eating Disorders (ED), Avoidant/Restrictive Food Intake Disorder (ARFID), Eye Movement Desensitization Reprocessing (EMDR), Cognitive Behavioral Therapy (CBT)

\section{ÖZET}

Travmatik yaşam olayları yeme bozukluklarını (YB) tetikleyebilen etiyolojik faktörler arasında yer alır. Bu çalışmada, Göz Hareketleri ile Duyarsızlaştırma ve Yeniden isşleme (EMDR) terapisi ve Bilişsel Davranışçı Terapi (BDT) kombinasyonunun, travmatik deneyimler sonucu gelişen YB semptomlarını taşıyan iki genç kız üzerindeki etkilerini inceledik.

Oldukça benzer yeme şikayetleri ile iki kadın hasta kliniğe başvurdu. Her ikisi de boğazlarına yiyecek takılacağı,bunun ardından nefes almada güçlük çekecekleri ve kalp atışlarının hızlanacağı korkularını taşıyordu. $\mathrm{Bu}$ korkuları yeme esnasında yutkunamamaya yol açıyordu.. ilk görüşmelerde danışanlar boğazlarıa yiyecek tıkaması sonucu geçici bir süre nefes alamamaya ilişkin geçmiş travmatik olaylardan bahsetti. Bu nedenle EMDR terapisi ile birlikte BDT uyguladık. Her iki hastanın da yedi seans EMDR ve 9 seans BDT ile tedavi edilmesinin ardından semptomlar minimum düzeye indi. Bu vaka çalışmasında, EMDR terapisi ve BDT birleşimi ile geçmiş travmanın YB semptomları üzerindeki etkisini ortadan kaldırarak etkili sonuçlar elde edildi.

Anahtar Sözcükler: Yeme Bozuklukları (YB), Kaçıngan/Kısıtlı Yiyecek Alımı Bozukluğu (KKYAB), Göz Hareketleri ile Duyarsızlaştırma ve Yeniden İşleme (EMDR), Bilişsel Davranışçı Terapi (BDT) 
Two cases with avoidant/restrictive food intake disorder: Effectiveness of EMDR and CBT combination on eating disorders

\section{INTRODUCTION}

In the US, $50 \%$ of teenage girls and $30 \%$ of teenage boys engage in unhealthy weight control methods such as skipping meals, fasting, using substances, vomiting, and taking laxatives (1). Different therapies are used to treat ED, but their efficacy is controversial. There might be a variety of causes behind $\mathrm{ED}$, among which are often traumatic or adverse experiences.

According to Lejonclou and his collegues, the prevalence of traumatic events in ED patients is not at all low(2). Tagay and his colleagues found that patients experiencing more intense PTSD symptoms also have more severe ED symptomatology (3). In summary, there appears to be a frequent correlation between traumatic events and suffering from $\mathrm{ED}$, a clinical reality requiring new treatment considerations. At this point, interventions that successfully resolve the pathology of ED stemming from traumatic events may provide relief to those who are suffering.

Eye Movement Desensitization Reprocessing (EMDR) is a psychotherapeutic treatment, originally pioneered in the 1980s by Francine Shapiro to treat Post Traumatic Stress Disorder (PTSD) (4). EMDR treatment targets emotional reactions, negative mindscapes, and constant habits through bilateral (right and left hemispheres) stimulation (BLS) of the brain. On average, EMDR therapy requires approximately eight to twelve sessions for a trauma (5). It includes an identification of unprocessed negative thoughts and the reprocessing of traumatic events, which disturb clients in present time. With BLS techniques, EMDR stimulates a mind state similar to that of REM sleep, providing a consolidation process in the brain, which desensitizes painful or traumatic events (6). EMDR increases the functionality of traumatized people and can be used in the treatment of a variety of psychological problems.

One of the commonly used treatment options for a number of mental disorders including ED is Cognitive Behavioral Therapy (CBT) (7). The purpose of CBT is reappraising of unhelpful thoughts and behaviors with more encouraging ones to pro- vide clients better functioning lives. In addition to other mental and physical disorders, remarkable improvements had been observed on eating pathology using CBT (8). CBT treatment has been applied for 16 to 20 sessions over the course of 4 to 6 months (9). It is a well-established and widely used therapy for psychological disorders. In this present study, we applied EMDR therapy and CBT to two young female patients who had symptoms of Avoidant/Restrictive Food Intake Disorder (ARFID), a subtype of ED, stemming from their past negative eating experiences.

In the diagnostic and statistical manual-fifth edition (DSM-5), one of the most remarkable changes to the ED classification included the replacement of feeding disorder of infancy or early childhood with a more inclusive diagnosis named as "avoidant/restrictive food intake disorder" (ARFID). As DSM-5 criteria suggests, patients with ARFID suffer from severe feeding disturbances and display at least one of the following symptoms: significant weight loss, significant nutritional deficiency, dependence on enteral feeding or nutritional supplements, and/or a marked interference in psychosocial functioning. Unlike patients with anorexia and bulimia nervosa (AN and $\mathrm{BN}$ ), patients with ARFID are without preoccupation with body weight/shape(10). Moreover, they are not engaged in ways of losing weight, yet there is a visible lack of interest in eating or food, food avoidance based on sensory characteristics, or preoccupations including concerns about unwanted consequences of eating (such as vomiting) (10). Currently, the research background supporting this diagnosis is infrequently encountered, as prior classification systems would likely not have allowed clinicians to capture or report on such patients (11).

Treatment required seven sessions of EMDR and nine sessions of CBT. Both patients showed a marked improvement in their eating habits and had the impact of traumatic events attenuated. It can be proposed that the integration of EMDR and CBT has a promising potential to be useful in treating ED and their subtypes, including ARFID. In addition, combination of these treatment methods was effective in preventing ARFID from escalating into more severe forms of ED. 


\section{Previous Studies}

In 2014, Tagay and colleagues documented comorbidity of PTSD and ED in women with anorexia nervosa and bulimia nervosa, and proposed an association between traumatization and $\operatorname{ED}(3)$. They also suggested early detection of traumatic experiences and PTSD in patients with ED, and inclusion of PTSD treatment in cases of comorbidity.

Many studies had been conducted on the efficacy of CBT on $\operatorname{ED}(12,13)$. One of the studies was focusing on how CBT affects subtypes of ED such as anorexia nervosa (AN), bulimia nervosa (BN), and binge eating disorder (BED), and compares it with other treatment approaches. A study found that CBT was slightly more helpful in the treatment of $\mathrm{BN}$ and $\mathrm{BED}$ when compared to other treatment options with the greatest improvement being when CBT was combined with fluoxetine(14).Another study proposes that CBT may be the best choice of therapy on Eating Disorders Not Otherwise Specified (NOS) and BN(15). Both studies noted above investigate the role of CBT on ED subtypes, however, none of them studied on ARFID.

With respect to EMDR, a study by Bloomgarden and Colagero investigated effectiveness of EMDR in treating patients with $\mathrm{ED}(16)$. There were two groups of patients in this study: the first group of patients received standard residential eating treatment alone (SRT), while the second group was treated with SRT and EMDR therapy combined. Their results demonstrated that those receiving EMDR therapy with SRT showed less stress about negative body images after 3 months and 12 months follow-ups compared to those receiving SRT alone. This study demonstrated that EMDR therapy could be utilized to address negative body image in ED treatment. However, this study was conducted specifically on negative body image symptoms of ED patients.

\section{Present Study}

In the literature very few studies can be found about the effectiveness of EMDR and CBT in the treatment of ED and its subtypes. The current study describes how in two similar cases symptoms of ARFID were reduced to a minimum level by the application of seven EMDR sessions and nine CBT sessions. Moreover, treatment may have prevented a progression from ARFID to more severe forms of ED such as non-fat phobic restricting type of anorexia nervosa by stopping significant weight loss and reducing food avoidance behaviors. Beck Depression Inventory (BDI) and Beck Anxiety (BAI) inventory scales were applied in the treatment process. BDI and BAI are scales that measure symptoms of anxiety and depression $(17,18)$. Turkish validity studies were performed $(19,20)$.

\section{Assessment and Treatment Processes}

Implementation of the EMDR Protocol: EMDR was seen as an appropriate treatment component, given the traumatic eating experiences of both patients. Each EMDR session lasts 90 minutes. However, due to high level of therapeutic needs in the clinic, session time length that could be set for each patient being up to 60 minutes, sessions lasted around 60 minutes. Validity of Cognition (VoC), and Subjective Unit of Disturbance (SUD) scales were used to measure the felt truthfulness of a preferred Positive Cognition (1-7) and the level of distress (0-10) respectively (21).

CBT Treatment Protocol: During the therapy sessions, the therapist encourages the patient to express his or her feelings, beliefs, and thoughts about the troubling situation. Guided discovery and Socratic questioning techniques are examples to therapeutic techniques used for patients to notice their own automatic thoughts. CBT sessions endure 50 minutes for each therapy session, and therapy number varies in accordance with the severity of the distress .

\section{Patient A}

Miss A was a Caucasian, 18 year-old, female college student, born in Istanbul, Turkey. She applied to the psychiatric services of Haydarpaşa Numune Hospital with complaints of inability to eat and unwanted weight loss, resulting in generalized and recent acts of aggression. When Miss A first came to the clinic, her appearance resembled an anorexia 
Two cases with avoidant/restrictive food intake disorder: Effectiveness of EMDR and CBT combination on eating disorders

nervosa patient. Her Body Mass Index (BMI) was 17, and her weight was 39 kilograms (85 lbs).

She reported that when she was 14 the food stuck in her throat while eating a pastry, leading to breathing difficulty. Two months after this event, she started to feel afraid while eating that she would be unable to swallow, choke on her food and die due to asphyxiation. Because of this fear, she began to restrict her food intake, ate soft food, or processed food into purée or fluid. Her fear and subsequent avoidant eating behaviors continued. Because of her sense that something was stuck in her throat, she received diagnostic endoscopy on three separate occasions; yet no physical cause for the sensation was found.

Additionally, BDI and BAI were administered to both patients before and after treatment. Miss A scored 14 and 4 on BDI, and 35 and 12 on BAI respectively, demonstrating a decrease in her depression and anxiety levels (see Figure 1 in Figures part at the end).

Miss A experienced very intense ruminations. Before applying to our clinic, she had been taking Olanzapine and Fluoxetine, both prescribed during her previous treatment regimen. Her Minnesota Multiphasic Personality Inventory (MMPI) report revealed that her Axis-I implied depressive disorders with anxiety distress, while her Axis-II revealed type $\mathrm{C}$ personality traits. She did not present with any form of medical disease.

EMDR Sessions: Patient A described a memory as follows: "When I was 14, a piece of pastry stuck in my throat, and I couldn't breathe for a while." This being a target memory, the images of food getting stuck and not being able to breathe was reprocessed. The EMDR protocol was employed and strictly adhered to for each of the sessions that followed.

Before the first session of EMDR therapy, her Beck Anxiety Inventory (BAI) score was 35 . In the session, the patient expressed her negative cognition (NC) as "I'm helpless", then, for her positive cognition (PC) she chose "I can get rid of it." At the beginning of the session, her VoC was 2 and her
SUD was 7. At the end of the first session, the VoC had already increased to 6 , the SUD had decreased to 2, and her BAI score dropped to 12 . In the third session of EMDR therapy, the same memory was processed during a 60-minute session. Her initial VoC was 5 for the PC, the SUD was at a 5, and the BAI was 12. Eye movements were applied for twelve sets, resulting in a VoC of 7, a SUD of 1, and a BAI of 7. The Fifth EMDR session followed the same procedure as previously. At the beginning of the session, the VoC was 5 and the SUD was 5. Her VoC reached 7 and her SUD decreased to 0 by the end of the session.

CBT sessions: In the general sense, CBT sessions covered traumatic event of Miss A and her point of view about the situation. Guided discovery and Socratic questioning techniques helped automatic thoughts to be noticed by the patient. After nine sessions of CBT, the patient started to bring a new perspective about her traumatic memory.

Last Two EMDR Sessions: The main purpose of the last two EMDR sessions was to heal the remaining, emotional vividness of the memory. In the beginning of sixth EMDR session, her SUD score was 4, and her negative belief about herself was "I am weak and helpless." Her preferred PC was "These kinds of things can happen to anyone" with an accompanying $\mathrm{VoC}$ of 6 . At the end of the session, the SUD was 0 and VoC was 7. The seventh session of EMDR began with a SUD of 3 and a VoC of 5 . After EMDR treatment, her SUD decreased to 0 and her VoC increased to 7.

\section{Patient C}

Miss C was a Caucasian, 20-year old, female college student. She applied to our psychiatry clinic with complaints of having a sense of food stuck in her throat whenever she ate during the last three months. This resulted in a food intake restriction and a loss of $3.5 \mathrm{~kg}$ (7.72 lbs.) in a month's time, and brought her to the edge of an underweight status, while feeling very anxious before and during eating. Overall, she began to experience depression and a loss of self-confidence. During the pre-treatment assessment and interview, she recalled an incident at the age of 10 or 11, when half of an ice 
Figure 1. Miss A Pre-Treatment and Post-Treatment Assessment Results

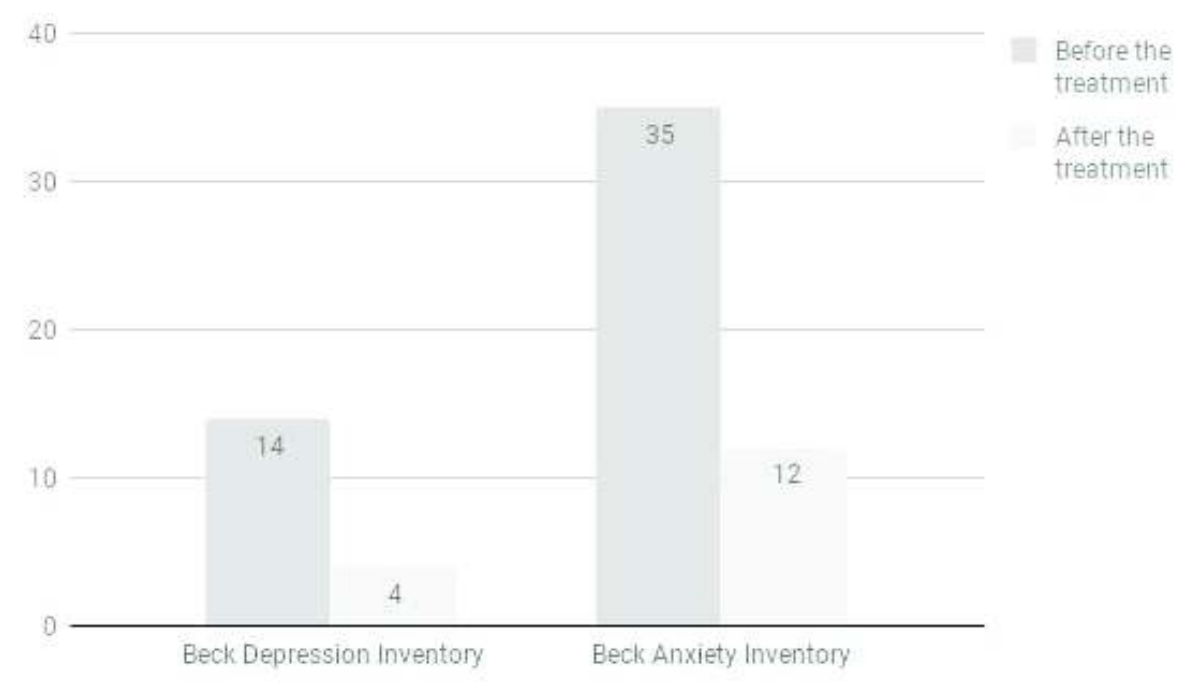

cream cone was stuck in her throat after her cousin forced her to eat the ice cream as fast as possible.

Not surprisingly, her BDI score was 21, while her BAI score was 35 . To alleviate her presenting complaints, $5 \mathrm{mg}$ Rexapin, and $20 \mathrm{mg}$ Prozac were administered. She had been taking Olanzapine before coming to our clinic, which was discontinued with the introduction of Rexapin and Prozac. Her mood was euthymic, and medical examinations did not reveal any concerns. Her MMPI test results revealed possible dependent personality traits on Axis II.
Before starting the first EMDR session, Miss C spoke about her past experience of not being able to swallow. When she was 11 , she was eating ice cream with her cousin, and the cousin forced her to eat the ice cream as quickly as possible. When she tried to swallow the ice cream too quickly, almost half of the ice cream cone stuck in her throat, hence temporarily obstructing her ability to breathe. As a treatment plan, EMDR and CBT had been planned for her. First of all, five sessions of EMDR therapy have been applied to her. Hereupon, nine sessions of CBT was recommended for the re-evaluation of her situation from a different perspective. Then, two more EMDR sessions were applied

Figure 2. Miss C Pre-Treatment and Post-Treatment Assessment Results

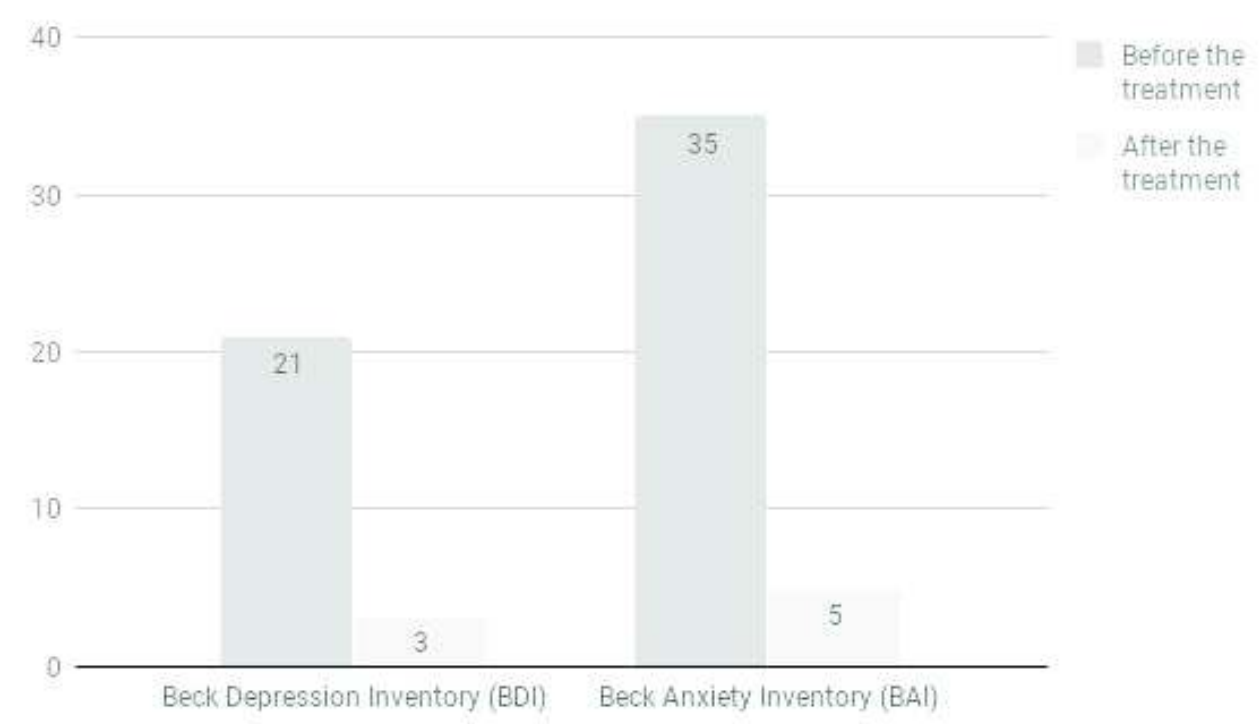


Two cases with avoidant/restrictive food intake disorder: Effectiveness of EMDR and CBT combination on eating disorders

and the treatment has ended.

EMDR Sessions: Beck's inventories were administered at the start. BAI score was 35, and BDI score was 21. EMDR sessions then focused in detail on "the ice cream cone" memory. At the beginning of the first session, the NC was "I am helpless, and I will die"; her PC about the situation was "I can cope with the sense, even if the food in reality is stuck in my throat." Before the application of visual bilateral stimulation, the $\mathrm{VoC}$ was 4 , and the SUD score was 8 . After 22 sets of eye movements, the VoC was 5, and the SUD was 4. The third session of EMDR lasted 85 minutes. In the beginning of the session, the BAI score was 23, and BDI score was 16, the SUD was 6 , and the $\mathrm{VoC}$ was 5 . At the conclusion of the session, the SUD was 0 , and the VoC was 7.

The fifth EMDR therapy was definitive for the patient. Her SUD was 5, and VoC was 5 before that EMDR session. At the session's end, her SUD decreased to 0 and the $\mathrm{VoC}$ increased to 7 . Her BAI score was 18, and her BDI score was 12.

CBT Sessions: CBT sessions had been beneficial for Miss $\mathrm{C}$ on recognizing her dysfunctional thoughts, and becoming aware of her automatic thoughts about herself and her traumatic experience. Nine sessions of CBT were practiced with the patient, and her ruminations have decreased remarkably. Her feelings of inadequacy disappeared to a large extent during the treatment period. Her social relations had been uplifted, and she became more efficient.

Last Two EMDR Sessions: After a productive CBT period, Miss $\mathrm{C}$ still experienced disturbance due to the traumatic event. This situation affected her daily life quality. Therefore, the decision was made to administer two more EMDR sessions. In her sixth EMDR session, she began with a SUD of 6 with the NC of "I cannot handle it without getting help." Her PC was "I can get help," and its VoC was 1. During EMDR processing, the patient recalled other memories, hence, with the impression that those memories she started to recall and bring into therapy might have influenced her latter traumatic experiences, these memories were seen noteworthy and became the focus of therapy. The patient recalled a memory in which she blamed herself for her mother's illness. In the beginning, the SUD score was 7, and her thought about herself was "I am guilty". Her preferred thought was "it was not my fault" with a VoC of 1 . After BLS, her SUD score had reduced to 6 , and her $\mathrm{VoC}$ had gone up to 3 .

The last session of EMDR was related to her pattern of self-blaming, in this case involving her boyfriend. Her first experience of difficulty swallowing following the initial traumatic event took place at her boyfriend's house where she ingested a painkiller. As a result, she began to fear that she might die at his house. This led to guilt about possibly causing troubles or negative consequences for her boyfriend. She said this thought was very stressful. The SUD score for this event was 9, and her NC was "I am a guilty person". Her alternative PC was "I am a normal person", with a VoC of 5. During eye movement sets, Miss C expressed her fear of death. Lastly, she received psycho-education. At the end of the treatment process, her BAI score was 5, and her BDI score was 3.

\section{DISCUSSION}

In the present study, two patients who suffer from ARFID(10) resulting from traumatic eating events were treated with the combination of EMDR and CBT therapies. In previous studies, trauma-related ED could be improved with the help of EMDR therapy, however, ARFID was not one of EDs that is treated with EMDR therapy. This study introduces the possibility of treating other types of ED with EMDR.

With bilateral eye movements and EMDR therapy being utilized, emotional vividness and general disturbance due to the traumatic events was reduced, generating greater optimism with regard to the adverse memory itself and the present triggers. Cognitive recovery procured through CBT sessions helped minimize avoidant eating behaviors. Consequently, both patients reached their normal weight. 


\section{Limitations of the Study}

The first limitation is the sample size. The study was undertaken with only two patients, thus reducing its generalizability.

The second limitation is that EMDR and CBT treatments were concurrently implemented. Implementation of additional and specific treatment approaches for ED or ARFID are recommended for further studies.

Another limitation of the study is related to the use of pharmacotherapy to increase patient weight for a considerable period of time. Future studies might try treating ARFID or other ED subtypes without medication and therapy being utilized at the same time.

\section{CONCLUSION}

During follow-up, Miss A said she could now easily eat a greater variety of foods, including solid foods with a few exceptions, without thinking about something getting stuck in her throat. After the fourth EMDR session, BMI of Miss A increased to 20 from 17. Miss A reported that her eating habits had returned to normal. She pointed out that she could even eat meatballs and pasta, food she couldn't tolerate before treatment without being anxious.

Throughout follow-up sessions, Miss $\mathrm{C}$ reported she did not suffer from her swallowing problems anymore. She started to perceive the ice cream memory as an ordinary situation. She stopped her restrictive eating behavior and began to take in a normal amount of calories. Although her recovery period was not free of problems given her dependent personality traits, she still increased the amount and type of food she consumed, and has gained $10 \mathrm{~kg}$ (22.2 lbs.).

In summary, the present study aims to investigate effects of EMDR and CBT combination in treatment of ARFID. The study analyzed two similar cases, both treated similarly. Predictably, both patients showed a considerable recovery from
ARFID symptoms. Follow-ups of both patients are still in progress. The study gives indication that EMDR and CBT combination may help to decrease the symptomology of ARFID in a short amount of time, while possibly decreasing the necessity of pharmacotherapy. It can also be hypothesized that the potential risk of developing anorexia nervosa or bulimia nervosa symptoms as a result of ARFID is significantly lessened. In conclusion, the application of EMDR and CBT therapies seems to offer potentially effective treatment for ED and its subtypes.

Correspondence address: M.D. Alisan Burak Yasar, Marmara University Hospital, Psychiatry Clinic, Istanbul, Turkey burakyasar54@gmail.com 
Two cases with avoidant/restrictive food intake disorder: Effectiveness of EMDR and CBT combination on eating disorders

\section{REFERENCES}

1. Gallivan HR. Teens, social media and body image. Park, Nicollett Melrose Center. 2014

2. Lejonclou A, Nilsson D, Holmqvist R. Variants of potentially traumatizing life events in eating disorder patients. Psychological Trauma: Theory, Research, Practice, and Policy. 2014;6:661.

3. Tagay S, Schlottbohm E, Reyes-Rodriguez ML, Repic N, Senf W. Eating disorders, trauma, PTSD, and psychosocial resources. Eating disorders. 2014;22:33-49.

4. Shapiro F. Efficacy of the eye movement desensitization procedure in the treatment of traumatic memories. Journal of traumatic stress. 1989;2:199-223.

5. Shapiro F. Eye movement desensitization and reprocessing (EMDR): Basic principles, protocols, and procedures: Guilford Press; 2001.

6. Logie R. EMDR-more than just a therapy for PTSD. The Psychologist. 2014;27:512-6.

7. Murphy R, Straebler S, Cooper Z, Fairburn CG. Cognitive behavioral therapy for eating disorders. Psychiatric Clinics. 2010;33:611-27.

8. Turner H, Marshall E, Wood F, Stopa L, Waller G. CBT for eating disorders: The impact of early changes in eating pathology on later changes in personality pathology, anxiety and depression. Behaviour research and therapy. 2016;77:1-6.

9. Vaz AR, Conceição E, Machado PP. Guided self-help CBT treatment for bulimic disorders: Effectiveness and clinically significant change. Psychotherapy Research. 2013;23:324-32.

10. Association AP. Diagnostic and statistical manual of mental disorders (DSM-5®): American Psychiatric Pub; 2013.

11. Kreipe RE, Palomaki A. Beyond picky eating: avoidant/restrictive food intake disorder. Current psychiatry reports. 2012;14:421-31.

12. Hofmann SG, Asnaani A, Vonk IJ, Sawyer AT, Fang A. The efficacy of cognitive behavioral therapy: A review of meta-analyses. Cognitive therapy and research. 2012;36:427-40.

13. Hay PP, Bacaltchuk J, Stefano S, Kashyap P. Psychological treatments for bulimia nervosa and binging. Cochrane Database of Systematic Reviews. 2009(4).

14. Brown TA, Keel PK. Current and emerging directions in the treatment of eating disorders. Substance abuse: research and treatment. 2012;6:SART. S7864.

15. Schumann S-A. Suspect an eating disorder? Suggest CBT. The Journal of family practice. 2009;58:265.

16. Bloomgarden A, Calogero RM. A randomized experimental test of the efficacy of EMDR treatment on negative body image in eating disorder inpatients. Eating disorders. 2008;16:418-27.

17. Beck AT, Steer RA, Carbin MG. Psychometric properties of the Beck Depression Inventory: Twenty-five years of evaluation. Clinical psychology review. 1988;8:77-100.

18. Beck AT, Steer R. Beck anxiety inventory (BAI). BiB 2010. $1988 ; 54$.

19. Hisli N. Beck Depresyon Envanterinin gecerliligi uzerine bit calisma (A study on the validity of Beck Depression Inventory.). Psikoloji Dergisi. 1988;6:118-22.

20. Ulusoy M, Sahin NH, Erkmen H. the Beck Anxiety Inventory: Psychometric Properties. Journal of cognitive psychotherapy. 1998;12:2.

21. Jarero I, Uribe S. The EMDR protocol for recent critical incidents: Brief report of an application in a human massacre situation. Journal of EMDR Practice and Research. 2011;5:15665 . 